\title{
XXXVIII. On Sir H. Davy's Safe-lamp for mines
}

\section{John George Children Esq. F.R.S.}

To cite this article: John George Children Esq. F.R.S. (1816) XXXVIII. On Sir H. Davy's Safe-lamp for mines, Philosophical Magazine Series 1, 48:221, 189-196, DOI: 10.1080/14786441608637640

To link to this article: http://dx.doi.org/10.1080/14786441608637640

曲 Published online: 27 Jul 2009.

Submit your article to this journal $\pi$

LII Article views: 2

Q View related articles 두 
Fig. 6 and 7.-6 being the manner in which the platform appears, or apertures through which the flowers pass; and fig. 7 . shows the buds without the platform: and fig. 6 and 7 both together at AA.

Fig. 8,9 , and 10 , are the three specimens, showing the very curious manner the folds of the thin matter will draw in : and fig. $S^{*}, 9^{*}$, and $10^{*}$, are specimens of the root of the enanthe, the angelica, and the hieracium spondylium; out of which the foregoing figures were taken.

Fig. $1 \mathrm{i}$, and $11 \%$ are the specimens showing the manner the line of life is formed, when folded in trees either so or in fig. 5: and $11 *$ the manner it is folded in herbaceous plants.

Fig. 12. Manner in which flowers mount in the stem of herbaceous plants : first in little bouquets, then collecting in large, as at $e e e$, when the stem lengthens, and they open.

Fig.13, showing the apertures through which the flowers mount. Fig. 14, the stem of the leaf of the poplars.

Perhaps I had most wisely avoided giving the figures described at figs. 8,9 and 10 , as carrying so little probability in their appearance; - but when I first began to dissect and imitate the vegetable tribe, I most absolutely determined that I' would literally draw all I saw, without exaggeration and without diminishing the objects presented to my sight, let them be ever so extraordinary. No one had before taken a review of these objects,-all that was supposed to be known, was very little more than conjecture, except the seeds: no one had attempted to take the specimens trogressively - what the interior was, therefore, "was (till now) a secret;" and after sixteen years constant dissection I cannot be accused of ignorance. With this observation I leave it to public opinion.

\section{On Sir H. Davy's Safe-lamp for Mines, By John George Children, Esq. F.R.S.}

\section{To Mr. Tilloch.}

SIR, - I READ with some degree of indignation, in the Annals of Philosophy for July last, a paper by a Mr. Longmire, calling itself Remarks, \&c. on Sir Humphry Davy's Safe-lamp for the Colliers; and I addressed a letter to Dr. Thomson on the subject. That letter the learned Editor of the above Journal has thought fit to suppress; - nor should I have considered it worth while to take even this brief notice of so weak an attempt to injure one of the most important inventions with which enlightened genius has ever blessed the world, but have left it to perish in its own 
insignificance and be forgotten, had I not found the subject pursued in a letter from a Mr. Holmes, in the succeeding number of the same publication. The avowed intention of the author of this paper, and the experiments on which he pretends to ground his objections, seem to me to require some animadversion, not indeed from the liberality of the former, nor the reliance (as I shall show presently) that is to be placed on the fidelity of the latter, or the inferences deduced from them; but from the possibility that, if they pass altogether unnoticed, an opinion may prevail, among those who have not sufficiently considered the subject, that they are founded in truth. As the results of Mr. Holmes's experiments are diametrically the reverse of similar ones by Sir Humphry himself, I thought it right in the first place to examine their nccuracy; and with that view I submitted the safe-lamp to the most rigorous trials, and under circumstances as analogous to those which prevail in the coalmines as I could devise. For this purpose, I caused a cylinder of strong tin plate to be constructed fourteen inches in length and five in diameter, having four tubes in the bottom half an inch wide, and one inch long each, placed two and two opposite one another and one inch from the circunference; and three other pairs of similar size, fixed in the sides of the cylinder, each tybe on the same level being opposite to its fellow. The lowest pair were three inches from the bottom, the middle six, and the upper pair nine inches distant from the same point. By means of these tubes I conld expose the lamp to atmospheres of various degrees of inflammability, and I could also force the gas into the cylinder with greater or less violence, and at different heights, from bladders connected with stop-cocks, as well as project into it such substances, in fine powder, either above, below, or on a level with the flame of the lamp, as might be thought likely to communicate explosions, through the wire-gauze, to the atmosphere surrounding it;-and I could distinctly observe the phænomena through small squares of glass fixed in the sides, so as to afford a full view of what passed in the interior of the lanthorn. Not having any of the real fire-dany of the mines, I substituted for it the more inflammable gas obtained from the distillation of coal, and consequently the trials of the safety of the instrument became so much the more severe. The lamp I employed was made by Mr. Newman of Lisle-street. It is 'nine inches high, and the gauze cylinder, which is constructed of simple iron wire, is $.1 \frac{1}{2}$ inch in diameter-the diameter of the wire being $\frac{1}{83} \mathrm{~d}$ of an inch, and the apertures, of which there are 900 to the square inch, $\frac{1}{30}$ th. This lamp gives an excellent light with spermaceti oil, which continues undiminished many hours.-I will frst briefy mention Mr. Holmes's experiments, 
and then state those which I made. I should perhaps have rather given the credit of these experiments to Mr. Ryan, as it seems it was he who first made them; but as he "practised on a lamp of only one inch diameter," he coincided with Mr. Holmes in opinion that his trials were unfuir ; and $\mathrm{Mr}$. Holmes having procured a lamp from Newman, the following experiments were made by himself and Mr. Ryan, partly at the gas-works in Dorsetstreet, and partly at a chemist's, in the presence of four other gentlemen.-I quote Mr. Holmes's words:

"I tried it first over a small gas tube, with coal-dust and powder, which ignited the gas outside; next with coal-dust alone, which after repeated trials produced the same results, and left an inflammation at the end of the tube."

"On inverting a teacup over the cylinder so as to produce a slight compression of the gas, it exploded from coal-dust several times."

"We then went to a chemist's and foreed some gas from a bladder against one side of the cylinder, while gas from another bladder was gently pressed on the opposite side: in a short time the gas on the outside infiamed;-this I compare to a blower, although the power we were able to use was very inferior to what would be given by the velocity of a blower under ground."- I I found that the flame of the wick would not penetrate the gauze cylinder, but the inflammation of the gas would, when acted upon by a strong current of air."

I shall now state my own experiments:-I suspended the safelamp in the centre of the lanthorn, at about two inches from the bottom, the four bottom apertures and the top of the lanthorn being open-I then forced coal-gas, from a bladder, with all the violence I could into the lanthorn through one of the lowest side apertures, an assistant at the same time throwing in atmospheric air from another bladder, through the middle aperture, on the opposite side, the other lateral apertures being closed. In a few seconds, about two inches of the wire gauze became red hot, and by continuing the blast from each bladder it rose almost to whiteness, the heat being greatest at the side opposite the jet of atmospheric air. - At this point the exterior gas exploded. In a former experiment of the same kind, in which the heat of the wire was not raised above a low red heat, no explosion ensued.

Mr. Holmes says he "cannot find that even this distinguished chemist" (Sir H. Davy) "has been able to explain why flame will not flow through small apertures."

Mr. Holmes cannot have taken much pains in his search; for in the first part of the Philosophical Transactions for the present year, at page 117, Sir Humphry says as follows:

"If a piece of wire-gauze sieve is held over a flame of a lamp 
or of coal-gas, it prevents the flame from passing it, and the phænomenon is precisely similar to that exhibited by the wiregauze cylinders; the air passing through is found very hot, for it will convert paper into charcoal; and it is an explosive mixture, for it will inflame if a lighted taper is presented to it, but it is cooled lelow the explosive point by passing through wires even red hot, and by being mixed with a considerable quantity of air comparatively cold. The real temperature of visible flame is perhaps as high as any we are acquainted with-Mr. Tennant was in the habit of showing an experiment, which demonstrates the intensity of its heat. He used to fuse a snall filament of platinum in the flame of a common candle; and it is proved by many facts, that a stream of air may be made to render a metallic body white hot, yet not be itself luminous." -I forbear to quote more of this interesting paper, though I recommend the whole to the careful perusal both of $\mathrm{Mr}$. Holmes and the other opposers of the " wonderful lamp."-The experiment I have detailed is correctly explained hy the ahove reasoning. Even at a red heat the wire cooled the gas below the point of inflammation,--but not when the heat nearly reached to whiteness, and accordingly explosion then ensued. Mr. Holmes has not, after all, made any great liscovery in finding that the inflammation of the gas will penetrate the wire-gauze when reacted on by a strong current of air-for Sir Humphry Davy has stated it himself in his "'Additional Practical Observations," printed first for distribution amongst the miners, and which may also be found in the Philosophical Magazine for July last. - I quote a few lines from that paper on the subject: "When indeed a strong current of coal-gas is driven from a blowpipe so as to make wire-gauze of 676 apertures strongly red hot in the atmosphere, the flame from this pipe may be passed through it whilst it is strongly red hot; but this is owing to the power which wires strongly ignited possess of inflaming coal-gas, and they have no such effect on genuine fire-damp; and a stream of gas burning in the atmosphere acting on a small quantity of matter, is entirely' different from an explosive mixture, which is uniform within the lamp."

But the more serious charges against the lamp are the explosions likely to be occasioned by the fine coal-dust, \&c. floating in the atmosphere of the mine; for against this evil, no caution could provide a remedy; whereas, from what has been stated, it is evident, that most extraordinary carelessness must co-operate with most extraordinary circumstances, to make an explosion possible from the mere flame of the fire-damp burning in the lamp. We must therefore inquire how correct the experiments of $\mathrm{Mr}$. Holmes are; and we shall see presently, that 
when fairly stated and rationally investigated, not one of them militates in the slightest degree against the perfect safety of the lamp.-And here it may very probably be urged, and with perfect truth, that all this was known before, from Bir Humphry D̈avy's own experiments, and consequently that mine are quite superfluous.-I readily admit it. Sir Humphry, at the first suggestion that danger was apprehended by the miners from the coal-dust, immediately submitted the lamp to rigorous trials, to prove how well or ill their fears were founded. He repeatedly threw coal-dust, powdered rosin, and witch meal, through lamps burning in more explosive mixtures than ever occur in coal-mines; and though he kept these substances floating in the explosive atmosphere, and heaped them upon the top of the lamp when it was red hot, yet he never could communicate explosions by means of them. Phosphorus and sulphur only produced that effect by being applied to the outside of the lamp, and even they required to be in large quantities and llown upon by a current of fresh air. -Vide Philos. Magaxine, vol. xlviii. p.54. The liberal and enlightened will not be disposed to question the truth of this statement, from one whose candour and accuracy are equally acknowledged ; and to such all further evidence is work of supererogation,- - to them 1 do not write:but we have seen, unhappily, that all are not of that class; and though I do not hope to reclaim the perverse and malicious, I notwithstanding am anxious, as far as my feeble efforts can assist, to prevent others really desirous of the truth, from being misled into the path of error and unfounded scepticism. Feelings of attachment towards a man whom I glory in calling my friend, cannot but create in me a warm interest for all that tends to exalt the lustre of his well-acquired fame; - but beyond the feelings of friendship, or the fame of my friend, $I$ an anxious for the prevalence of truth, and that one of the greatest benefits science ever conferred on humanity should shed the full infuence of its blessing, spite of the malicious insinuations of ignorance and envy.-I return to the experiments.

Exp. 1. I suspended the lamp in my lanthorn and threw in the coal-gas from a bladder as hefore; and when the gauze cylinder was filled with flame, a mixture of about three parts of finely levigated coal-dust and one part of gunpowder-dust was thrown into the lanthorn, which occasioned an abundance of sparks within the gauze cylinder, but no explosion of the exterior gas.

Exp. 2. I fixed a small tray of very thin eopper-plate, containing the mixture of coal-dust and gunpowder, about three inehes above the wick of the lamp within the gauze cylinder, suspended the lamp in the lanthorn, and threw in the gas as

Vol, 48, No. 221. Sept. 1816. 
before. The mixture took fire in the tray as soon as enveloped by the inflamed gas, and burnt with a very large flame mixed with innumerable scintillations; but no explosion (though the experiment was continued till all the gas of a very large bladder was expended) could be produced.

Exp. 3. The lamp and lanthoris being arranged as before, the gas was thrown in at one of the lowest side apertures, and the coal-dust and gunpowder at an upper one, and a current of air forced on the inflamed gas from another bladder through the opposite middle opening. The whole burned with a very full and strong flame, and the scintillations were so violent as almost to resemble the tail of a sky-rocket, and the wire-gauze soon became red hot, but no explosion ensued. Had I continued the experiment till the wire-gauze became nearly whitehot, an explosion of course would have followed; but it would take place as certainly without the coal-dust. It is therefore fairly established that coal-dust cannot communicate flame to the external air, when the lamp is immersed in the most explosive mixtures.

I repeated the last experiment with the double lamps, and also without the coal-dust, and used every endeavour to produce an explosion, but without effect. I raised the wire-gauzes to a dull red heat, but could not get them hot enough to suffer flame to pass through. In every case possible, therefore, the double lamp is perfectly secure; and unless in the hands of an idiot or a madman, the single is hardiy less so;-nothing but a current of air, directing the flame with considerable force to one point, can hent the gauze sufficiently for flame to traverse it;-and should such a current be met with in the mine, it must inevitably extinguish the lamp, and thus be itself the safeguard from its own danger.

Mr.Holmes, however, caused explosions by holding the lamp over a smàl gas tube, and projecting coal-dust and gunpowder and even coal-dust alone, on it; and I understand the same effect has been produced in the laboratory of the Royal Institution. In those experiments, I am told the lamp was held nearly horizontally over the pipe of the large gasometer (and consequently the full heat of the flame from the wick of the lainp constantly directed to one point), and coal-dust thrown on the top of the gauze. Mr. Holmes does not state in what direction he held his lamp. In this arrangement it is obvious that a current of fresh air round the lamp is established, the coal-dust is heated red by contact with the wire-gauze, and its ignition increased by the current of air; and thus it reaches the temperature at which it can explode the circumambient gas; but this will not happen, without that partial current, which can-never prevail in the mine; nor I believe will it happon at all, if the lamps 
be held vertically; at least I made repeated attempts to produce an explosion with the lamp in that position, the gas being thrown into it in the free atmosphere in vain, although I kept the whole cylinder a considerable time completely filled with flame, and the powdered mixture constantly projected into it ; but when inclined, I succeeded. A mixture of gunpowder with the coal was however necessary; without it I could obtain no explosion, nor with it could I always succeed; never, indeed, till after the gas had been thrown in long enough to heat the wire very hot; but,-and it proves the accuracy of the reasoning on the experinent, - when once an explosion was effected, it might be repeated at pleasure, provided the gauze cylinder was not suffered to cool. With the double lamps I could not by any means produce an explosion, whatever position it was held in.

I placed coal-dust and gunpowder on the top of the wiregauze cylinder suspended in the lanthorn, and threw in the coalgas. The whole cylinder was filled with flame, and the upper part became red hot. The mixture burned, and tinrew off sparks, but occasioned no explosion. On putting a lighted match into the lanthorn the gas immediately exploded with violence.

The same experiment was repeated with the addition of a jet of atmospheric air thrown from a bladder with a small blowpipe on the ignited coal and powder dust-but neither in this case did any explosion ensue.

$A$ few words more, and I have done. Mr. Holmes seems inclimed to hint that Sir Humphry Davy has borrowed the idea of his lamp from Sterenson's, and talks of the "G alteration" he has made on it, "by weaving the holes instead of having them punched." If Mr. Holmes were acquainted with the progress of the investigation by which Sir Humphry was led, step by step, from successively established facts to the present perfection of the instrument, he would know that $\mathrm{Sir} \mathrm{H}$. borrowed no idea concerning it from Mr. Stevenson or any one else. It was early in last October that $\mathrm{Sir} H$ umphry communicated in corfidence to me the discovery of the principle which was the base of his subsequent reasonings, viz. the narrow limits in which the proportions of atmospheric air and fire-damp can be combined so as to afford an explosive mixture; - and on the following day he showed Mr. Brande and myself the experiments which confirmed its accuracy. Like every thing else that Sir Humphry has done, this lamp is the result of consequences most sagaciously deduced from causes most ingeniously and diligently inquired into;-and is it to be borne, that the labours of such a man are to be made the subject for every envious caviller to vent his spleen on? or that it should be insinuated, that their results are plagiarisms and pilforings, from the accidental (however happy) dis. 
196 On certain Experiments with Sir H. Davy's Safe-lamp.

covery of one who (confessedly even by Mr. Holmes himself) is ignorant of the principles of his own invention?

$\mathrm{Mr}$. Holmes's last paragraph is calculated only to excite feelings I will not indulge in, and I shall not give it any other notice than to observe, that $I$ believe the assertions it contains are as inaecurate as they are illiberal,

I have the honour to remain, sir, Your very obedient servant, John Grokge ChILDREN.

P. S. - I should have made this cotmmunication earlier, had not absence from home obliged me to defer the experiments till too late for its insertion in your last number.

XXXIX. On certain Experiments with Sir H. Davy's Safelamp, reported to have been made at the Gas Establishment in Dorset-street. By WILliam KNIGHT, Esq. the Manager of that Establishment.

\section{To Mr. Tilloch.}

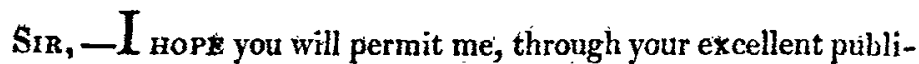
cation, to endeavour to remove any unfavourable impression which may have been made by a paper on Sir H. Davy's Safety-lamp, in the August Number of the Annals of Philosophy, by a Mr. Holmes, relative to some experiments conducted at the Gas Establishment in Dorset-street, with which I am connected.

Mr. Holmes speaks of a visit to the works for the purpose of trying experiments on Sir H. Davy's safety-lamp, and mentions persons who were present at the trials. Does Mr. Holmes publish their names, to attach importance to his liberal investigation? If he does, it is fair to ask what credit his experiments derive from the presence of Mr. Wheatcroft, who is employed here to pay the workmen; Mr. Morris, who superintends the works by night; and Mr. May, of whom I never heard before he obtained importance in Mr. Holmes's letter: How Mr. Holmes had aecess to the works, I know not; nor would I or any other proprietor knowingly lend ourselves, or the establishment, to experiments not openly conducted. Whenever gentlemen, who are men of seience, have wished to visit the works, an application has been usually made to me as engineer, and I. have always been ready to afford free inspection, and give every, facility to experiments; but in this instance I never heard of $\mathrm{Mr}$. Holmes or his visit till I saw his own report in the Annals of Philosophy, and that only yesterday, when the last number was put into my hands. As the active partner and manager of the 